\title{
FEATURES OF EXPERIENCING LONELINESS IN OLD AGE
}

\author{
ELENA G. UMANSKAYA, NATALIA A. TSVETKOVA
}

CORRESPONDENCE: ELENA.UMANSKAYA@MAIL.RU TEL.:+7-910-400-77-96

Keywords: Ioneliness, experience, old age, adaptation, lifemeaningful orientations, self-attitude.

\section{Introduction}

The study showed that there are two social factors affecting the experience of loneliness in the old age. One of these factors is the place of residence (a metropolis or a small city in province). The second one is living conditions (in a special organization such as a social nursing home or in a family of the elderly person). A theoretical analysis of the literature on the problem of experiencing loneliness allowed us to identify two features in the experience of loneliness by different people. The first feature is that loneliness is characterized by a constant human desire to belong to society. This is expressed in the desire of the individual person to be like all the people around him, to be a social unit. The second feature of the experience of loneliness is that loneliness is characterized by a person's desire to escape from loneliness is characterized by a person's desire to escape from society. This is expressed in the desire of a person to be an individual, to be a unique person. in psychological iiterature, loneliness is often described as a negative experience. However, there are authors who consider the phenomenon of loneliness from a positive point of view.

E. Fromm sees the reasons for loneliness in the anthropological contradiction between man and nature, in the existential conditions of human existence. Loneliness is a natural givenness of human existence, which cannot be avoided, and attempts to combat it can only strengthen these experiences. The more a person aspires to freedom, the more he moves away from nature (from the external world), which is a conflict of the existential needs of human existence - the desire for freedom (the need for identity) and the desire for security (the need for making connections). The study of this problem allows us to consider the psychological characteristics of an elderly person, specific to a particular place of residence and different living conditions. Interest arises in the study of various aspects of the influence of social tactors on the experience of loneliness - broader factors, like the geographical place of residence, and narrower as the "house" in which an elderly person lives. The purpose of our work is to establish the psychological characteristics of experiencing the loneliness of an elderly person, depending on various social factors. Social living conditions and contacts with peers are the main factors that can influence the assessment of oneself and one's life as an aging person. The availability and accessibility of social life reduces the level of loneliness. Any common activity with peers increases the self-control of an elderly person and increases his sense of social importance and social belonging.
2. Materials and Methods

As research methods, we used the following 4 psychodiagnostic methods. The method of diagnosing the level of subjective feeling of loneliness (authors - D. Russell, M. Ferguson) allowed us to identify levels of loneliness in the elderly. The method of diagnosing socio-psychological adaptation (authors - K. Rogers, D. Diamond) allowed us to diagnose the socio-psychological adaptation of older people, their adaptive mechanisms, focused on harmonizing the relationship of the individual with the environment. The test of life meaningful orientations (author - D. A. Leontiev) made it possible to diagnose the semantic sphere of the elderly. The self-test questionnaire (authors - V.V. Stolin, S.P. Pantileev) made it possible to diagnose the formation of self-attitude in old age.

The study involved 80 elderly people aged 84 to 93 years ( 58 women and 22 men). In accordance with the purpose of the study, we divided the whole group of 80 elderly persons into the following 4 equal groups:

1. Elderly people living in the social house (the nursing home) in Moscow - 20 people;

2. Elderly people visiting the social service center, but living at home with their family in Moscow - 20 people;

3. Elderly people living in the gerontological center in the Yaroslavl region - 20 people;

4. Elderly people visiting a social service center, but living at home with their family in the Yaroslavl region - 20 people.

In our research we used a comparative method of identifying differences in the studied features of the study sample. The reliability and validity of the research results were ensured by the correct application of modern methods of mathematical statistics in the processing of empirical data using the SPSS Statistics program; informative analysis of the identified indicators. Statistical processing of empirical data was carried out using the following methods of mathematical statistics: Mann-Whitney U-test and factor analysis.
3.Results

Based on various combinations of social factors (a place of residence and living conditions) together with the psychological characteristics of older people, we identified 4 structures of experiencing loneliness in the old age, which we called by the following way: "Social loneliness", "Loneliness as integrity-|", "Loneliness as avoidance", "Independent loneliness"

The first structure named "Social loneliness" is typical for elderly people living in a megalopolis in a nursing home, who show a tendency to experience high loneliness, which differs from the least noticeable tendency to experience loneliness in all other groups of empirical research. The elderly people in this first group have a level of loneliness experience associated with such psychological characteristics as adaptability, self-acceptance, emotional comfort. The absence or unavailability of social life increases the level of oneliness. Any ioint activity with peers increases the selfcontrol of the elderly person and increases his/her sense of social significance.

The second structure named "Loneliness as integrity-I" is typical for elderly people living in the metropolis in their families. Oider people in this second group show a less pronounced tendency to experience loneliness than older people in the first group. Their experience of loneliness is associated with such psychological characteristics as adaptability, self-acceptance, internal control, domination, sympathy and interest to themselves. The cause of the experience of loneliness is the quality of a person's own selfesteem, his attitude to himself. Those elderly people who have found the activity that is adequate for their age as well as is interesting for them, experience loneliness more rarely. Their a sense of self-control can reduce the number of stressful moments from experiencing loneliness.

The third structure named "Solitude avoidance" is typical to the elderly people living in the province at the social nursing home. These older people show similar results of the severity of the experience of loneliness as the older people living in a metropolis in a family environment. In both cases, the experience of loneliness is associated with such psychological characteristics as rejection of others, escapism. Thus, in the presence of a family and a wide range of family ties, an elderly person voluntarily chooses a lonely lifestyle.

The fourth structure named "Independent loneliness" is characteristic of the older people living in the province in their family environment. They show a tendency to low level of loneliness. As the factor analysis shown the loneliness of these people is not related to the psychological characteristics studied in our work. 